\title{
Vinte anos da pós-graduação em Design no Brasil: novos rumos
}

Luiz Antonio Luzio Coelho (Currículo Lattes)

\section{ESTE TRABALHO ESTÁ DIVIDIDO EM CINCO PARTES:}

1. Integração GRA e PÓS;

2. A pós-graduação em Design na PUC-Rio;

3. A importância da pesquisa no Design;

4. Precursores do desenvolvimento da formação dos cursos em Design;

5. O atual paradigma da pesquisa em Design: perspectivas de estudo.

O tempo deixa suas marcas e por meio destas conhecemos o percurso trilhado. Como é natural, essas marcas podem constituir o norte para se decidir o que é preciso fazer, vez que representam 
carências e desafios passados que apontam para o que está à frente. Desta forma, este texto busca trazer o contexto do Design no momento da criação do primeiro programa de pós-graduação no país, com algumas informações que marcaram tal experiência'. Não o queremos apenas a título de registro, mas como memória que possa constituir vetor para novas estratégias de desenvolvimento da área.

\section{GRA E PÓS: COMPETIR OU INTEGRAR?}

Quando se cria um programa de pós-graduação, considera-se, às vezes, que a PÓS compete e, de certa forma, prejudica a graduação, já que se trata de um curso que exige mais investimento na formação de massa crítica e tem uma relação aluno/docente menos favorável e mais onerosa, carreando energia e recursos financeiros, sobretudo quando a GRA está repleta de problemas a resolver. Eu diria que problemas sempre existem e são, em realidade, o reflexo de nossos sonhos de aprimoramento. Vão sempre existir e sempre nos veremos atrás da busca de suas soluções. Somos seres que problematizam, e essa dinâmica de busca está em nossa natureza. Em realidade, muitas das soluções para uma GRA estão no salto para a PÓS. Melhoria de infraestrutura e apoio das agências de fomento para ações de ensino, pesquisa e produção científica, para citar dois casos, desembocam em soluções das lacunas da GRA. Portanto, projetos de pesquisa da PÓS representam oxigenação para o curso como um todo.

Se o projeto representa a oxigenação financeira, o graduando representa a oxigenação de mão de obra, a continuidade para a pesquisa e o reforço para manter o fluxo contínuo de pesquisadores.

\footnotetext{
${ }^{1}$ Neste texto, a palavra design (em caixa baixa) é usada para designar a atividade do designer enquanto projetista, sendo a palavra Design (em caixa alta) utilizada para referirse à disciplina e ao corpo de conhecimento que compreende a área dentro do ramo das Ciências Sociais Aplicadas.
} 
Pecando, talvez, por certo simplismo, eu diria que a integração entre alunos de GRA e PÓS e destes com docentes que atuam nos dois níveis é a pedra de toque do sucesso de um programa de Design. Pelo menos é uma das variáveis para a qualidade do programa, algo reconhecido pelo MEC e pela CAPES quando contabilizam a integração dos dois níveis na avaliação dos programas.

A integração entre graduação e pós-graduação não apenas é recomendada, mas dela depende o nível das pesquisas, uma vez que pesquisadores principiantes têm a oportunidade de atingir excelência com maior rapidez. Quanto mais cedo o aluno da graduação, com potencial para o trabalho investigativo-científico, tiver contato com grupos mais maduros de pesquisa, maior o rendimento do trabalho e melhor o nível dos resultados obtidos. A troca entre pesquisadores iniciantes e veteranos torna-se, assim, essencial.

O profissional que sai da graduação nesse ambiente de trocas com a PÓS ganha a perspectiva da crítica para além da simples produção. Passa a ser um profissional antenado, que vai querer saber dos desdobramentos de seu trabalho. Não fecha o projeto no protótipo, que acaba, muitas vezes, sendo o ponto final dos TCCs.

Para atingir o estágio consolidado de sua pesquisa, um programa de PÓS necessita de estratégias de desenvolvimento da investigação científica na GRA:

1. Identificando onde estão as excelências a partir do que já se vem fazendo (quais os grupos de pesquisa existentes e quais os projetos isolados);

2. Tomando providências de incentivar a pesquisa na GRA (implica vontade política);

3. Identificando pesquisadores em potencial dentre os alunos da GRA;

4. Criando e promovendo pontos de escoamento, quer tornando público os espaços e veículos de divulgação (revistas, congressos, 
exposições, concursos etc.), quer fomentando a geração de produtos, relatórios de pesquisa ou patentes resultantes da pesquisa ou facilitando a clássica produção científica (artigos, palestras, oficinas, livros etc.);

5. Buscando mecanismos de alargamento de possibilidades de fomento: bolsas de iniciação científica (tais como PIBIC, do CNPq, ou as ICs, das FAPs), bolsas internas, bolsas de fundações privadas, bolsas de projeto integrado, bolsas por cota etc. ou por meio de sistema de disciplina que dá créditos de pesquisa na grade da GRA (Introdução à Pesquisa ou Atividades Complementares);

6. Buscando mecanismos automáticos de manutenção desse processo por meio de funções especiais e equipes voltadas para gerir o sistema (coordenações específicas de pesquisa, desenvolvimento, iniciação científica, entre outras).

As oportunidades de um programa de pós-graduação constituem um catalizador positivo não somente para a GRA, mas para o curso como um todo. Os alunos da GRA de um programa que mantém a PÓS passam a contar com conhecimento e estrutura física potenciais que lhes abrem exponencialmente inserções no mercado, pois têm à disposição pessoal e recursos para uma formação diferenciada, mais individualizada, algo que a grade curricular da GRA não permite per se. Isso significa customização funcional para cada mercado e maiores oportunidades de colocação neste, independentemente de o aluno seguir a PÓS. É óbvio que a PÓS, pela titulação e conhecimentos que faculta, amplia oportunidades de ascensão salarial. Muitos dos mestrandos da PUC-Rio hoje - diferentemente do início de nossa PÓS, quando havia uma visível demanda reprimida de formação para a academia - são egressos da indústria ou do setor de serviços, que procuram o mestrado para fins de ascensão empresarial. 
Finalmente, a busca da consolidação se faz por meio da conscientização da importância da pesquisa para a IES e para o aluno e cria uma cultura de pesquisa, com especial atenção à ética e aspectos de recepção, desuso e sustentabilidade.

\section{PARA ALÉM DA INTEGRAÇÃO}

A excelência de um programa acadêmico como um todo, independentemente do foco isolado na graduação ou na pósgraduação, pressupõe que os egressos do curso sejam incentivados em direção a outras buscas e conquistas. Esse objetivo é atingido por meio de:

1. Fomento da relação do Design com outros campos de pesquisa, conforme já valorizado neste texto. A formação hoje deve ser multifacetada. Sem perder foco na especialização enquanto opção de determinado programa de GRA (formação profissional com ênfases específicas), não se deve deixar de considerar um fato da contemporaneidade: as convergências, em especial nas convergências de tecnologia e de serviços (JENKINS, 2009). No design, por exemplo, é o caso do profissional multimídia, que trabalha dentro de um concerto de tecnologias;

2. Busca pela associação interinstitucional, assim como a cooperação entre pesquisadores nacionais e estrangeiros. Há hoje no Brasil, patrocinados pela CAPES, programas de redes de pesquisa com grande número de países e de IES renomadas na área do design. Lançar mão dessa integração ajuda na obtenção de melhores resultados;

3. Incentivo do aluno a participar de associações científicas e seus encontros periódicos, o que resulta em potencial para redes interuniversitárias e caminho para a formação de grupos 
de pesquisa de excelência internacional. Os esforços dessas associações, que mantêm relações com acadêmicos de outros países e promovem a ponte entre estes e pesquisadores brasileiros, ajudam na mudança do patamar da pesquisa em Design.

\section{O IMPACTO DA CRIAÇÃO DA PÓS-GRADUAÇÃO NO DESIGN DA PUC-RIO}

A história da pós-graduação na PUC-Rio passou por algumas fases e representou vontade política da instituição e o esforço do corpo docente e administração do Departamento de Artes \& Design, aliados ao empenho dos pós-graduandos que passaram pelo programa nesses vinte anos.

$1^{\text {a }}$ fase (1994-1996): apesar de termos a ideia clara do que seria um programa de pós-graduação em face da experiência de formação dos próprios doutores que constituíram o programa e do feedback com a experiências de outros departamentos da universidade, não poderíamos imaginar como seria lidar com um campo que ainda não havia sido experimentado no Brasil; como seria trabalhar com o Design em nível de PÓS diante da percepção que outros tinham da área com base na prática profissional, o único balizador que se tinha até então. Foi este, sobretudo, um período de adaptação ao sistema da pós-graduação definido pela CAPES, algo que era novo para nós.

$2^{\text {a }}$ fase (1997-1999): com os primeiros mestres formados, esse foi o período de integração formal. O ingresso de novos alunos, anualmente, somados aos pós-graduandos que já estavam no programa, constituiu o fluxo de formação pós-graduada e o aglutinamento em torno do orientador, simultaneamente à criação de alguns laboratórios e estabelecimentos de projetos isolados dos docentes do programa (patrocinados ou não). 


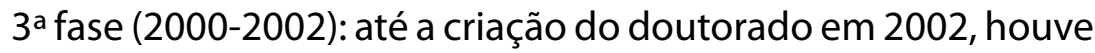
o aumento da massa crítica com a admissão de novos docentes no programa e a inauguração do Instituto de Pesquisa em Design (IPD), com laboratórios de PÓS e seus núcleos, além da organização de projetos que vieram integrar pesquisadores de diferentes laboratórios.

$4^{\text {a }}$ fase (2003-atual): esta vem sendo a fase da integração continuada, com maior organicidade entre alunos de GRA, PÓS e docentes do programa do DAD e de outras unidades da universidade e instituições de naturezas diversas fora da PUC-Rio. Foi o período do oferecimento de Doutorado interinstitucional (DINTER) e de estágios pós-doutorais, com mais intensa cooperação internacional. Também tivemos a criação do Programa de Graduação em Arquitetura e Urbanismo em conjunto com o Departamento de Engenharia Mecânica da PUC - hoje com mestrado stricto sensu reconhecido pela CAPES e constituindo um departamento independente do Design no organograma da universidade.

\section{A PESQUISA COMO BALIZADOR}

A ideia de design está intimamente ligada à de projeto, e a ideia deste, por sua vez, sugere aspectos de pesquisa aplicada compreendida em dado processo de concepção e fabricação. Mas por que mencionar aqui pesquisa associada ao design quando é comum ouvir-se dizer que design refere-se a um fazer, a um projetar, em vez - ou antes - de ser pensado enquanto um ramo particular do conhecimento com seu amplo espectro de indagações envolvendo a investigação científica? Eis, então, que me refiro a essa ideia de projeto como uma película que envolve a prática do design, mas que muitas vezes compreende aquilo que entendemos por pesquisa 
no sentido acadêmico. Não me refiro, obviamente, a um fazer baseado na repetição de um processo de fabricação. Repetir pode justificar um projeto, assim como um projeto pode sintetizar-se em se querer realizar um trabalho qualquer, em querer fazer algo para fins de aprendizagem. Em tais acepções, todavia, projeto não implica pesquisa, quando muito um processo com etapas planejadas. Em contraste, a pesquisa acadêmica representa, além de busca em si, geração de conhecimento por meio de análise cuidadosa de todo o processo: da relação entre variáveis à reflexão sobre causas e consequências da criação e da racionalização da metodologia com consciência dos porquês dos passos adotados até a consecução dos objetivos. Essa noção de pesquisa apaga os limites do que se entende por pesquisa pura e aplicada, restando apenas uma ideia de pesquisa. E é a essa noção de pesquisa a que me refiro. Tratase do tipo de pesquisa que percebo em boa parte dos projetos do Design realizados na academia. E aqui desejo deixar patente que estou convencido de que o Design pressupõe pesquisa científica não apenas nos cursos de pós-graduação, como seria pacífico de se aceitar, mas também em nível de graduação.

Hoje, em meados da segunda década do século XXI - e após vinte anos de história de pós-graduação em Design no Brasil - podese afirmar que não há dúvidas sobre a importância da pesquisa albergada pelo Design no país. Tanto para a comunidade acadêmica dos dezenove programas de PÓS - quinze stricto sensu e quatro lato sensu - comprometidos com a investigação científica diretamente, quanto para as agências governamentais ${ }^{2}$. Mas não foi assim no princípio, na época em que se começou a pensar na necessidade de criação de um mestrado stricto sensu a partir de meados dos anos

\footnotetext{
${ }^{2}$ Apenas a região Norte não possui PÓS em Design, lato ou stricto sensu: são seis na região Nordeste, um na região Centro-Oeste, cinco na região Sudeste e sete na região Sul.
} 
oitenta do século passado. O primeiro programa de pós-graduação stricto sensu em Design começou a funcionar na PUC-Rio em 1994. Naquela época, contudo, a formalização da PÓS pareceu não ter sido suficiente para atestar o foro investigativo-científico a que nos referimos em relação ao Design. A título de ilustração, narro um episódio ocorrido em agosto de 1995, quando dos seminários do PIBIC na instituição. Imediatamente após as apresentações dos bolsistas de Design - e em visível comparação aos trabalhos ali anteriormente apresentados por bolsistas de outras áreas, como Letras e Filosofia a avaliadora do CNPq elogiou nossos projetos do ponto de vista utilitário, mas indagou onde estaria assinalada a pesquisa científica além da práxis. Foi preciso que alguns docentes da área levantassem em defesa do método projetual e seus componentes de investigação pura e aplicada. Foi preciso dizer que adotamos, de fato, métodos científicos na condução de nossos trabalhos acadêmicos. Em realidade, sabemos nós que os projetos oriundos dos bancos das escolas de Design envolvem princípios semelhantes a qualquer projeto acadêmico, inclusive lançando mão de procedimentos tanto da área tecnológica quanto das áreas humana e social. E que talvez introduzam o estudante da graduação no processo de pesquisa mais cedo do que em outras áreas acadêmicas. Apesar disso, a visão do design como atividade profissionalizante impedia que se percebesse tal característica com clareza. O que, acredito, parecia constituir um óbice na obtenção de apoio por parte das agências de fomento. A não ser que - no momento de criação de nosso programa de pósgraduação - optássemos em criar um mestrado profissionalizante. ${ }^{3}$

\footnotetext{
${ }^{3}$ LEALI, Francisco. A lista negra da pós-graduação brasileira, Jornal do Brasil, Seção Brasil, de 29 out. 1995, p. 16, em que se lê que a CAPES previa apoio a programas que demonstrassem interesse nessa direção.
} 
Pouco antes da criação do mestrado em Design da PUC-Rio, surgiu um movimento coeso de um grupo de escolas de Design em torno da demonstração de seus métodos em questões de pesquisa. Criaram-se fóruns científicos para discutir o tema e decidir como sensibilizar os governos federal, estadual e municipal na adoção de políticas públicas. O movimento teve o propósito de dar rumo seguro à condução do ensino e pesquisa do Design. Um exemplo é o grupo de trabalho que organizou o primeiro congresso brasileiro de Design constituído por acadêmicos, com apoio do periódico científico Estudos em Design - cujo segundo número foi lançado nesse congresso - e por componentes da embrionária Associação de Ensino e Pesquisa de Nível Superior de Design do Brasil (AEnDBrasil), formalmente criada anos mais tarde, em 2005. Foi este o I P\&D Design, Congresso Brasileiro de Pesquisa e Desenvolvimento em Design, realizado em São Paulo em 1994, onde aconteceu um encontro com representantes da CEEARTES e onde se discutiu uma pauta de temas que subsidiariam o II e III Fóruns de Avaliação e Reformulação do Ensino Superior de Artes e Design. O II Fórum foi realizado em Campo Grande, MS, em 1994, e identificou a necessidade de critérios homogêneos de avaliação dos cursos de Design do país. Após elaborar um questionário-padrão, optou-se por sua aplicação, a título experimental, em onze IES que se voluntariaram para tal fim. Já o III Fórum aconteceu em Salvador, no mesmo ano.

Ao final do encontro em São Paulo, saiu-se com uma lista de mais de vinte itens, dos quais gostaria de citar cinco: 1) necessidade do estabelecimento de uma teoria e crítica do design; 2) necessidade do estabelecimento de uma teoria do projeto; 3 ) estabelecimento de infraestrutura adequada ao desempenho das atividades de ensino, pesquisa e prestação de serviços à comunidade nas instituições de ensino; 4) necessidade de discussão pormenorizada sobre o papel da 
pesquisa em Design; e 5) promoção do Design. Esses pontos foram retomados em foros específicos de encontros posteriores, como o P\&D (em sua décima quarta edição em 2014).

Cada fase dessa história, dentro e fora do âmbito acadêmico, vem representando cunhas de conquista de espaço com ministérios, agências de fomento, associações patronais e governos regionais, que, por sua vez, também vêm respondendo com ações induzidas para a oxigenação do Design enquanto campo de saber e investigação e enquanto profissão.

Seguiram-se outras associações e encontros, como o Encontro Nacional de Ensino Superior de Design (ENESD) ou o Congresso Internacional de Pesquisa em Design (CIPED), promovendo o incremento da pesquisa e buscando maior visibilidade e melhores condições para o desenvolvimento do ensino do Design no Brasil e no exterior. Hoje temos dezenas de grupos formados por pesquisadores e alunos do Design de diferentes subáreas, que promovem eventos regionais e internacionais. Para citar apenas alguns, temos o Congresso Internacional de Ergonomia e Usabilidade de Interfaces Humano-Tecnologia: Produto, Informações, Ambiente Construído e Transporte (ERGODesign-USIHC) ou o Congresso Internacional de Design de Informação e Congresso de Iniciação Científica em Design de Informação (CIDI-CONGIC), organizado pela Associação Brasileira de Design de Informação (SBDI), que também criou o periódico InfoDesign.

Fora do âmbito do Design, a própria academia percebia a atividade apenas como uma prática, que não carecia de abordagens investigativas de natureza científica, como acontecia com as áreas do chamado núcleo duro das ciências. Era também a época em que se discutiam os MBAs no país. 
A luta em direção ao stricto sensu e à validação do campo como pesquisa científica foi intensa. A decisão institucional era pelo stricto sensu. Havia uma clara e grande demanda reprimida de docentes para os cursos de Design que já existiam e que começavam a surgir na universidade brasileira. Muitos dos docentes que estavam compondo os novos programas de Design vinham de outras áreas da academia. Era preciso abrir espaço para que o Design pudesse adensar seus quadros acadêmicos e criar sua própria massa crítica para programas de pós-graduação emergentes. E assim se fez o PPGDesign da PUC-Rio.

\section{PARA ALÉM DA UNIVERSIDADE}

Seria injusto simplificar o assunto da investigação científica no ensino do Design somente a partir da investidura na criação de programas pós-graduados dos anos oitenta do século XX. A luta iniciase na formalização dos cursos superiores de graduação em Design no país, ocorrida nos anos cinquenta e sessenta do século passado e no processo de reconhecimento e posterior regulamentação da profissão de designer. Luta pelo amadurecimento da área e da atividade ainda em curso sob certos aspectos - liderada por associações e pessoas tenazes, sem as quais não teríamos alcançado as conquistas acadêmicas de hoje. Faz-se mister mencionar, outrossim, outro marco fora do âmbito universitário a partir da segunda metade dos anos setenta. Trata-se das atuações do Centro Nacional de Referência Cultural (CNRC), Fundação Nacional Pró-memória (FNPM), Secretaria de Cultura do MEC e Instituto do Patrimônio Histórico e Artístico Nacional (IPHAN), tendo à frente um designer, Aloísio Magalhães, dando relevo ao valor cultural do produto brasileiro e também contribuindo para a visibilidade da atividade e do profissional. Foi 
esse o embrião do atual movimento em relação a políticas públicas no âmbito do MinC, com repercussão positiva tanto para a academia quanto para a profissão de designer.

$\mathrm{Na}$ estrutura do MinC, existem hoje órgãos setoriais que elaboram planos específicos para submeter ao Conselho Nacional de Políticas Culturais (CNPC) e subsidiar a elaboração do Plano Nacional de Cultura (PNC). Em 2009, o design, moda, arte digital, artesanato, arquitetura e urbanismo foram incorporados ao plano de colegiados setoriais do Ministério da Cultura, e em 2010, deuse a I Pré-conferência Setorial de Design para, em 2012, criar-se o Colegiado Setorial de Design, cuja primeira reunião, em julho de 2013, elaborou o Plano Setorial de Design, depois incorporado à III Conferência Nacional de Cultura (CNC) em novembro de 2013, e definiu políticas públicas do PNC. Além das Conferências Nacionais, com participação de representantes locais e regionais, tem havido, as Conferências Estaduais de Cultura articuladas com as CNCs e com pautas exclusivas para o design (CARDOSO et al., 2014).

No caso do Rio de Janeiro, tem havido as Semanas do Design promovidas pelo setor privado com apoio do governo do estado. Tem havido ações induzidas por parte dos governos estadual e municipal tendo o Design como área estratégica de desenvolvimento regional. Criou-se, por exemplo, o Centro Carioca de Design, iniciativa do governo municipal, o Edital Pró-Design lançado pela Prefeitura do Rio ou Centro Design Rio (CDR), parceria entre os governos estadual e municipal e entidades patronais, MCT, SEBRAE, associações profissionais e instituições de ensino.

É preciso salientar, ainda, o trabalho desenvolvido pelo Laboratório Brasileiro de Desenho Industrial (LBDI). Esse órgão é o resultado da política do Ministério da Indústria, Comércio e Turismo, juntamente com o CNPq e a FINEP, que criaram, em 1984, três 
laboratórios regionais com a missão de cuidar da formação básica em Design para o setor produtivo. A ideia era que esses laboratórios pudessem atuar com empresas para aumentar a competitividade dos produtos e serviços nacionais, visando à substituição de importados e, assim, equilibrando a balança de pagamentos. Os órgãos foram criados no Sul, em Florianópolis; no Sudeste, em São Carlos; e no Nordeste em Campina Grande. Depois de três anos, sem demonstrar os resultados esperados, as entidades de São Paulo e da Paraíba foram extintas e, em 1988, o Laboratório Associado de Desenvolvimento de Produto/Desenho Industrial de Santa Catarina, então dirigido por Gui Bonsiepe, ganha o nome de LBDI, passa e a ser liderado por Eduardo Barroso Neto. Nesse tempo, o LBDI projeta-se nacionalmente, dando cursos e prestando assessoria técnica a empresas. Eventualmente, o CNPq afasta-se do projeto e transfere o LBDI para o SENAI. Em 1995, o governo federal cria o Programa Brasileiro de Design (PBD) aproveitando o know-how do LBDI, e em 1997 o SENAI absorve as ações do laboratório e o extingue (PEREIRA et al., 2010).

\section{O ATUAL PARADIGMA NA PESQUISA}

A grande maioria dos trabalhos de fim de semestre e monografias de pós-graduação - mestrado e doutorado - tem seu foco em temas específicos relativos a ramos clássicos do Design, tais como Comunicação ou Programação Visual, Comunicação Gráfica e Projeto de Produto. Por outro lado, percebe-se o despontar de subáreas de estudo que buscam equacionar aspectos relativos ao Design não ventilados até então. São trabalhos que tratam de enfoques simbólicos ou epistemológicos na recepção, emoção, espiritualidade, subjetividade, retórica etc. 
Que se diga que esse não vem a ser um fenômeno apenas do Design. Essas subáreas representam, na realidade, preocupações globais e também são verificadas em outros campos de conhecimento. Marcam, isto sim, um paradigma contemporâneo da ciência. O amadurecimento da pesquisa é um pré-requisito nesse contexto. É ele quem favorece incursões que acontecem quando já existe uma comunidade formada, que se interessa pelo tema, que o compartilha e que o alimenta no desdobramento da discussão. Vinte anos de pesquisa contínua, por meio dos programas de pós-graduação do Design e seus desdobramentos lógicos - eventos científicos, acordos interinstitucionais e publicações -, sem dúvida respondem pela expansão e qualidade dos trabalhos que vêm se somando nesse tempo.

O novo paradigma também advém do incremento e interesse no estudo das fronteiras semânticas e pragmáticas de determinado campo de conhecimento. Por sua vez, esse interesse promove o alargamento da abordagem desse campo para aspectos intra e extradisciplinares. No caso do Design, especificamente, não bastaria pensar na interface que a área tem em sua própria esfera de ação como, por exemplo, verificar como se dá o relacionamento entre o Design de Produto e o Design Gráfico ou entre estes e ciências ou matérias já incorporadas ao conjunto de disciplinas que figuram nas grades curriculares dos programas de graduação, como Proxemia, Biônica, Ergonomia, Semântica etc. As relações extradisciplinares têm evidenciado espaços potenciais privilegiados de investigação para nossos pesquisadores. Ao se examinar os desdobramentos de subáreas, como as mencionadas acima nos recentes eventos científicos do Design e nos assuntos neles tratados, notam-se tais preocupações e interesses. É natural que com o lastro de massa crítica expandido com que hoje contamos no Brasil, esses desdobramentos ocorram. 
Muito se tem discutido sobre abrangência do Design, a começar pela própria terminologia. Encontros acadêmicos mais recuados no tempo - antes mesmo da criação dos programas de pós-graduação em Design - buscaram palavras que melhor caracterizassem o campo de conhecimento por meio de um termo global que o tipificasse. A questão de se evitar palavras estrangeiras foi bastante discutida nesses foros. Falou-se em Projética, por exemplo. Apesar da intenção, o termo Design tornou-se mais proeminente, e eventualmente trabalhou-se a relação entre Design e Desenho Industrial, ambos termos aceitos, guardadas nuanças de sentido. Mais adiante, discutiuse sobre a abrangência do Design multi e transdisciplinarmente e agora se fala na transversalidade e na complexidade do Design, termos que abrangem a questão da polissemia - o morfema design enquanto substantivo ou verbo ou o termo enquanto carreira ou ofício etc. - que examinam a articulação entre profissão e atividade, e estabelecem relações com outras atividades e profissões, além de com outros campos do saber.

A complexidade no Design pode ser uma vantagem para o campo, sobretudo para a pesquisa, pois que diante do desafio das interfaces de profissões e atividades vizinhas e absorvidas pelo Design vislumbramos uma vasta temática a ser mais trabalhada, espaços potenciais privilegiados, conforme registro acima.

Outra questão sobre complexidade e transversalidade, resultante da natureza líquida do Design, diz respeito ao entendimento por parte das agências de fomento e a classificação do Design nas tabelas de áreas de conhecimento (BAUMAN, 2001). No CNPq, estamos situados em área própria (Desenho Industrial, com duas subáreas: Programação Visual e Desenho de Produto) dentro do grupo da Engenharia de Produção (com Metodologia de Projeto e do Produto, Gerência do Projeto e do Produto, Desenvolvimento 
de Produto), na grande área das Engenharias e no COENG para o Comitê de Assessoramento e Avaliação. Na CAPES, por outro lado, estamos localizados dentro das Ciências Sociais Aplicadas, com área independente (Desenho Industrial) e com a Arquitetura e Urbanismo para fins de avaliação.

Poder-se-ia alegar aqui que nos expandimos para outros campos de reflexão, que extrapolamos nossas fronteiras de ação, que "invadimos" searas alheias. A razão do "protesto" estaria no argumento de que tais campos constituíam domínios de saber e práticas de outras áreas acadêmicas. Entretanto, a expansão do Design deu-se por força de novas percepções e pelo surgimento de oportunidades a partir do adensamento da pesquisa, conforme apontado. Outros campos do saber e profissões, inclusive os mais tradicionais, também expandiram suas fronteiras, o que relativiza a afirmação de que o Design é mais interdisciplinar que outras áreas de conhecimento e ação. Assim, outras áreas, em diferentes graus de interdisciplinaridade, também "invadem" novos campos de interesse, o que parece contribuir para se deixar de lado a ideia de que Design caberia em todo lugar e, portanto, nenhum lugar e que não teria sua especificidade. Concluímos, então, que hoje o paradigma científico é outro e a questão das fronteiras parece tornar-se secundária ou sem sentido no atual cenário.

Vizinho das Artes, das Engenharias, da Comunicação Social, da Arquitetura, do Artesanato, por exemplo, o Design, desenvolveu sua própria práxis e elaborou seu corpo teórico a partir de reflexões anteriores. Passou a gerar conceitos próprios e práticas que o peculiarizam. Mas não em função de limites e fronteiras, mas em função do olhar e da sensibilidade que o designer desenvolve a partir de sua educação formal e dessas práticas. O que acontece com qualquer esfera de atividade humana. Sendo mais específico, 
eu diria que a peculiaridade do olhar do designer está, por exemplo, na preocupação com a identidade ou na combinação desta com aspectos como leiturabilidade e legibilidade, apenas duas marcas evidentes desse olhar.

Em relação à semântica dos termos que gravitam em torno do Design, o Programa de Design da PUC-Rio fez uma opção quando manteve a palavra Artes no título de seu departamento (Artes \& Design). Há algum tempo a unidade era chamada de Departamento de Artes e abrigava as habilitações de Comunicação Visual, Projeto de Produto e Licenciatura em Artes (Arte-educação). Eventualmente deixou de oferecer a licenciatura e criou as habilitações de Mídia Digital e Moda. Pouco antes dessa decisão, passou a adotar a palavra Design em seu título e não abriu mão do binômio Artes e Design. Outros programas, por meio do nome da unidade ou das áreas e subáreas de concentração, as Engenharias ou a Arquitetura e Urbanismo optaram por distintas denominações.

\section{NOVOS RUMOS...}

Ao se pensar nos novos caminhos do Design, ter-se-á de considerar não apenas o campo de atividade e o conhecimento que o envolve, isoladamente, mas a contemporaneidade com suas transformações. Diante dos olhos de uma realidade plasmada surgem denominações que nos indicam rumos diferentes para os profissionais e para a pesquisa; preparam-nos para interstícios do saber e zonas de ação até então inexistentes. Vislumbramos novos atores de uma realidade desconhecida para nós. Hoje o designer já está projetando para a Biotecnologia, criando artefatos que suprirão necessidades alimentares. O mercado fusionado vem ganhando seu contorno há algum tempo. Nesses vinte anos que nos separam do surgimento 
da pós-graduação no Design no Brasil, surgiram vários nichos de atividade projetual e de reflexão teórica. Sem entrar em detalhes do que são ou como surgiram para não agigantar este trabalho, citamos apenas alguns termos que se tornaram proeminentes no período: design de gestão, design estratégico, design de comunicação, design de informação, design de interação, design de interfaces, design de serviços, design universal, ecodesign, less is more, design centrado no usuário, design thinking, branding, open innovation, ideação no projeto, entre outros.

Considerando as mudanças contemporâneas, Daniel Bell fala no pós-industrialismo para caracterizar as transformações de ordem econômica, social e política vividas pelo século XX, chanceladas pelo desenvolvimento tecnológico. $O$ impacto deu-se nas relações sociais, nas relações de trabalho e na maneira como o cidadão passou a interagir com as instituições, inclusive o Estado (BELL, 2008).

Além de Bell, outros autores como Lyotard (1979), Giddens (1990) e Bauman (2000) falam na instabilidade que afetou a sensibilidade contemporânea após um período de certezas patrocinado pela Modernidade. Para Hall (2006), o século XX fragmentou noções de raça, etnia, sexualidade, nacionalidade e classe - e a própria noção da subjetividade - tidas como devidamente mapeadas e certificadas no período moderno (HALL, 2006). Para Sudjic, os novos modos de produção industrial e a publicidade inauguraram o darwinianismo no consumo: artefatos que existiam e eram largamente utilizados foram transformados radicalmente ou extintos, dentro de um sistema de substituição baseado na crença de que o novo é melhor e mais evoluído do que o antigo (SUDJIC, 2009). A substituição é tão célere que frustra a possibilidade identificação entre dono e objeto do período anterior, conforme aponta-se em outro texto (COELHO, 2002). 
Enquanto Bell (2008) acentua a noção de pós-industrialismo a partir da segunda metade do século $X X$, facultado pelo desenvolvimento da tecnologia da informação e comunicação, Giddens (1990) fala na globalização do mesmo período como o motor dessas transformações. A globalização vai responder pelo novo padrão de consumo e de relações sociais, que abole distâncias e antigas noções de tempo. O local e o global fundem-se e a relação de causa e efeito cede espaço para a reciprocidade de impactos. Embora a noção de centro e periferia permaneça, ditada pelo poder econômico, culturalmente a hegemonia desses centros de poder é abalada pelas novas possibilidades de troca. Nesta atmosfera cambiante, profissionais e pesquisadores precisam adequar-se e buscar caminhos.

É difícil antecipar os paradigmas que se avizinham. Temos certeza, entretanto, de que eles virão e que a tecnologia torna-se a molamestra nessa transformação. No atual ambiente profissional, em que já se vive a situação das multicarreiras, a tendência é a de que o movimento se amplie no futuro. $O$ designer de amanhã talvez venha a combinar sua formação projetual a outra que melhor represente seus anseios e perfil expandidos. Em meios às céleres mudanças que se avizinham, é de se imaginar que novos paradigmas surgirão - e mais rapidamente do que em momentos históricos anteriores. Com certeza, as pesquisas do Design continuarão a impulsionar mudanças no panorama acadêmico contribuindo para novas conquistas científicas. 


\section{REFERÊNCIAS}

BAUMAN, Z. Modernidade líquida. Rio de Janeiro: Zahar, 2001.

BELL, D. The Coming of Post-industrial Society. New York: Basic Books, 2008.

CARDOSO, E.; CURTIS, M.; SILVA, T.; ROLDO, L.; LINDEN, J. O papel do design(er) nas políticas públicas culturais.

COELHO, L. A. Tal objeto, tal dono. In: LOPES, L. P. M.; BASTOS, L. (Org.). Identidades, recortes multi e interdisciplinares. Campinas: Mercado das Letras, 2002, v. 1, p. 69-81.

ENSAIO. AVALIAÇÃO E POLÍTICAS PÚBLICAS EM EDUCAÇÃO. Rio de Janeiro: Fundação CESGRANRIO, v. 3, n. 6, jan./mar. 1995. Ensaios.

GIDDENS, A. The Consequences of Modernity. Stanford, CA: Stanford University Press, 1990.

HALL, S. A Identidade Cultural na Pós-Modernidade. 11.Ed. Tradução: Tomaz Tadeu da Silva; Guacira Lopes Louro. Rio de Janeiro: DP\&A Editora, 2006.

JENKINS, Henry. Cultura da convergência. 2. ed. São Paulo: Aleph, 2009.

LEALI, F A lista negra da pós-graduação brasileira. Jornal do Brasil, Rio de Janeiro, 29 out. 1995, Seção Brasil, p. 16.

LYOTARD, J. La condition postmoderne: rapport sur le savoir. Paris: Les Éditions de Minuit, 1979 (Collection Critique).

Ministério da Educação e do Desporto, Secretaria de Educação Superior, Comissão de especialistas de ensino de Artes e Design. Projeto de Avaliação dos cursos superiores de Artes e Design Relatório de 1994. Brasília, dezembro de 1994. 
PEREIRA, L. M; MEDEIROS, Maria Carolina; SILVA, José Carlos Plácido da. Laboratório Brasileiro de Design: uma revisão da sua importância histórica para o Design brasileiro. In: P\&D DESIGN, 9, 2010, São Paulo, ANAIS.

SUDJIC, D. The Language of Things: Design, Luxury, Fashion, Art: how we are seduced by the objects around us. London: Penguin Books, 2009. 